
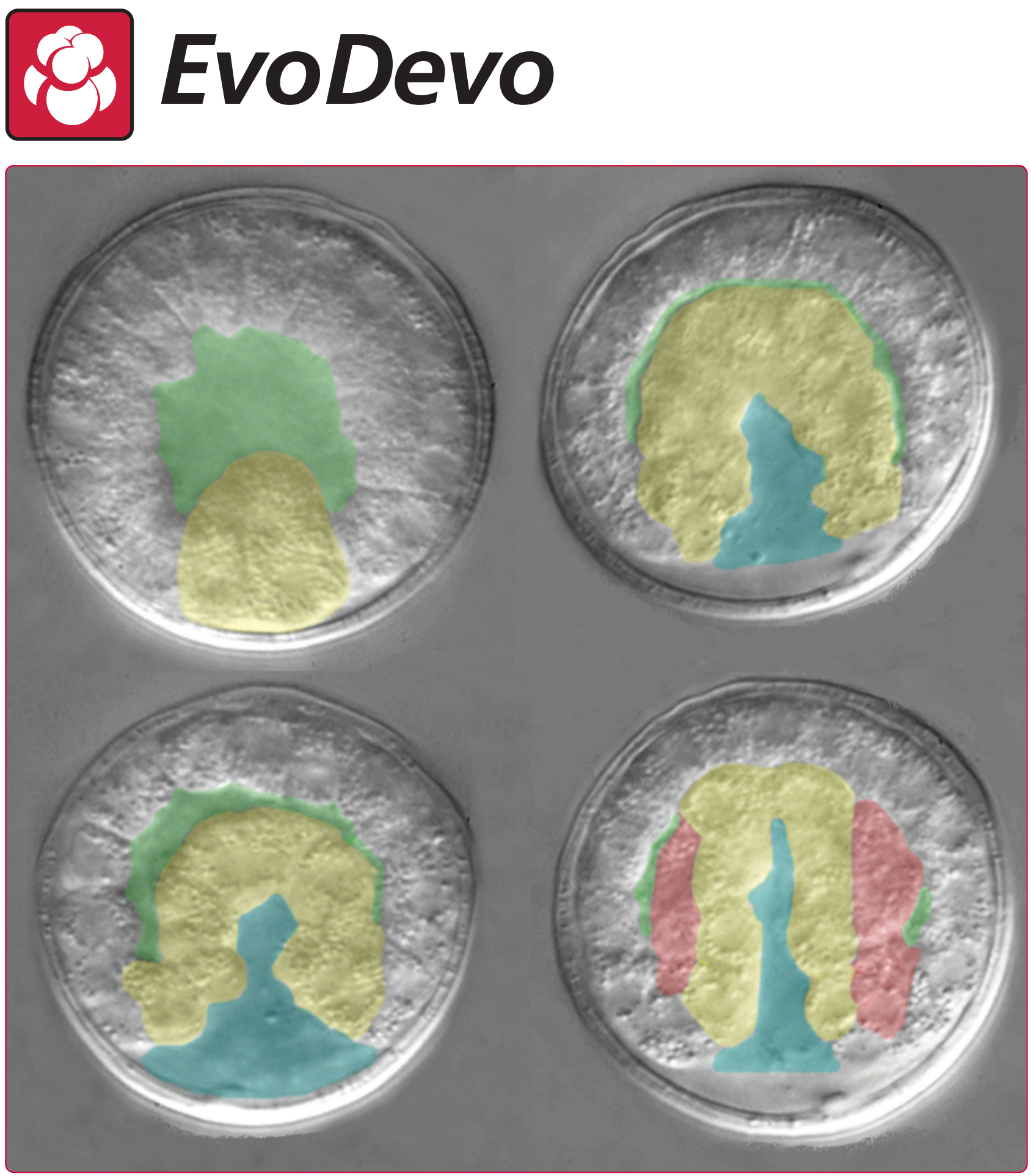

\title{
Evolution of embryonic development in nematodes
}

Schulze and Schierenberg 


\title{
Evolution of embryonic development in nematodes
}

\author{
Jens Schulze and Einhard Schierenberg
}

\begin{abstract}
Background: Nematodes can be subdivided into basal Enoplea (clades 1 and 2) and more derived Chromadorea (clades 3 to 12). Embryogenesis of Caenorhabditis elegans (clade 9) has been analyzed in most detail. Their establishment of polarity and asymmetric cleavage requires the differential localization of PAR proteins. Earlier studies on selected other nematodes revealed that embryonic development of nematodes is more diverse than the essentially invariant development of C. elegans and the classic study object Ascaris had suggested. To obtain a more detailed picture of variations and evolutionary trends we compared embryonic cell lineages and pattern formation in embryos of all 12 nematode clades.
\end{abstract}

Methods: The study was conducted using 4-D microscopy and 3-D modeling of developing embryos.

Results: We found dramatic differences compared to C. elegans in Enoplea but also considerable variations among Chromadorea. We discovered 'Polarity Organizing Centers' (POCs) that orient cleavage spindles along the anteriorposterior axis in distinct cells over consecutive cell generations. The resulting lineally arranged blastomeres represent a starting point for the establishment of bilateral symmetry within individual lineages. We can discern six different early cleavage types and suggest that these variations are due to modifications in the activity of the POCs in conjunction with changes in the distribution of PAR proteins. In addition, our studies indicate that lineage complexity advanced considerably during evolution, that is we observe trends towards an increase of somatic founder cells, from monoclonal to polyclonal lineages and from a variable (position-dependent) to an invariable (lineage-dependent) way of cell fate specification. In contrast to the early phase of embryogenesis, the second half ('morphogenesis') appears similar in all studied nematodes. Comparison of early cleavage between the basal nematode Tobrilus stefanskii and the tardigrade Hypsibius dujardini revealed surprising similarities indicating that the presence of POCs is not restricted to nematode embryos.

Conclusions: The pattern of cleavage, spatial arrangement and differentiation of cells diverged dramatically during the history of the phylum Nematoda without corresponding changes in the phenotype. While in all studied representatives the same distinctive developmental steps need to be taken, cell behavior leading to these is not conserved.

Keywords: nematode, embryogenesis, cell lineage, polarity, symmetry formation, cell specification, evolution, Tobrilus, Prionchulus, C. elegans

\section{Background}

Over many decades various suggestions have been made concerning phylogenetic relationships among nematodes. With the availability of an increasing number of gene sequences the phylogeny of this phylum was put on a more objective basis and resulted in major revisions of previous classifications [1-4]. In this work we

\footnotetext{
* Correspondence: e.schierenberg@uni-koeln.de

University of Cologne, Biocenter, Zuelpicher Str. 47b 50967 Köln, Germany
}

refer to the phylogeny of Holterman et al. [5], dividing the phylum Nematoda into 12 different clades (Figure 1a). We followed the proposal of De Ley and Blaxter [2] based on molecular and morphological criteria and subdivide nematodes into the two classes Enoplea (clades 1 and 2) and Chromadorea (clades 3 to 12). The former consists of two subclasses Enoplia (clade 1) and Dorylaimia (clade 2). Molecular and morphological data indicate that clade 1 comprises representatives closest to the

\section{() Biomed Central}




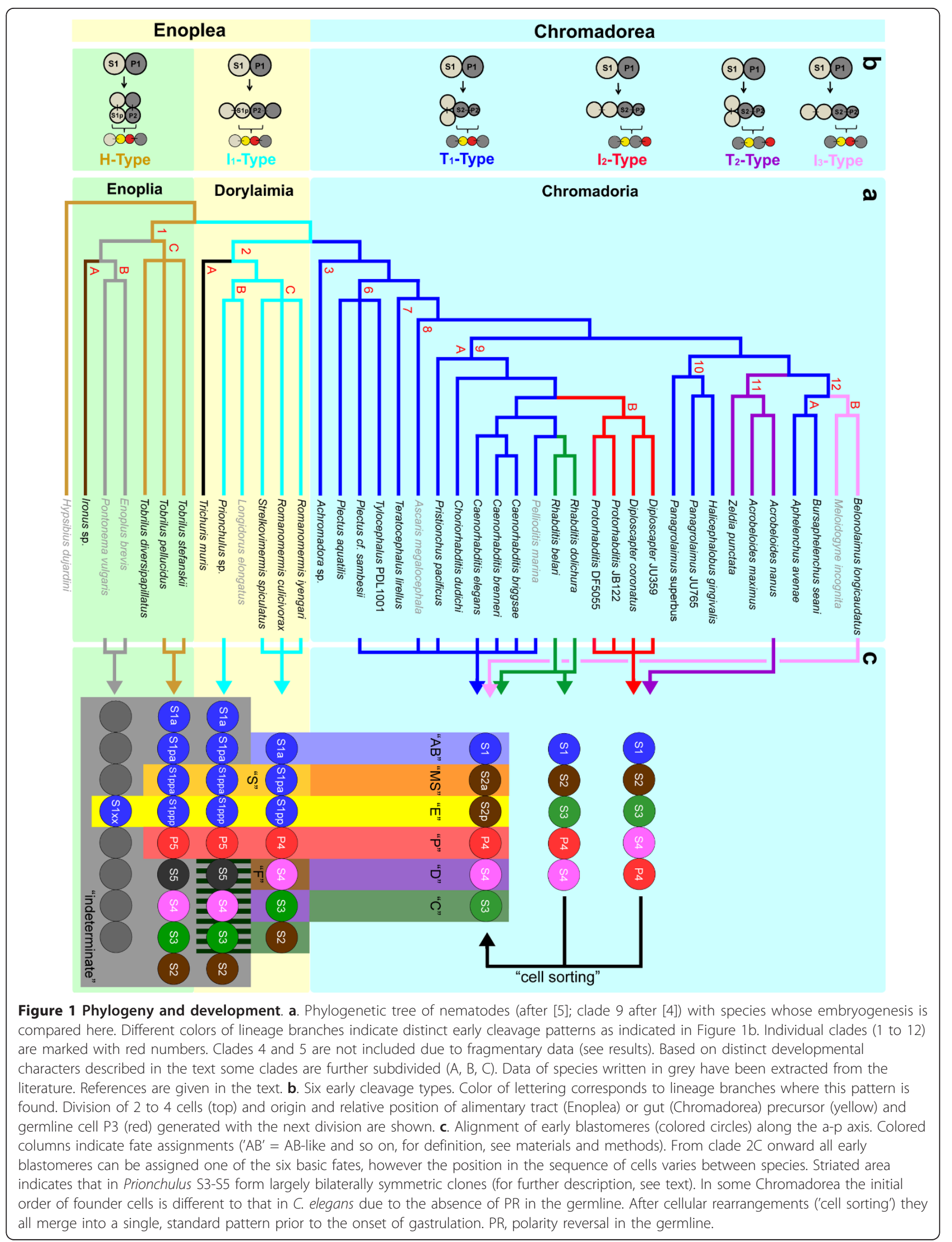


common ancestor of nematodes while Chromadorea include phylogenetically more derived species $[2,5,6]$.

Our current picture of embryonic development in nematodes is essentially shaped by the striking similarity between the classic model system Ascaris megalocephala (Clade 8; Figure 1a; $[7,8]$ ) and Caenorhabditis elegans (clade 9; [9]; http://www.wormbook.org). Work on $C$. elegans and its closer relatives has provided an initial insight into the recent evolution of embryonic and postembryonic development in clades 8 to 10 and discloses wide homologies in features, phenotypes and cell lineages [4,10-19]. Nevertheless, our understanding of the evolution of embryogenesis in the nematode phylum is still fragmentary. Species studied so far were usually chosen because of easy accessibility and amenable breeding conditions, and therefore represent a biased minority of the taxon. But generalizations from developmental characters of model organisms have to be taken with caution, because these organisms are often highly derived [20].

Embryonic studies revealed distinct developmental characters of nematode species and higher taxa that can be related to their phylogenetic position [14,21-26]. But not only inter-species but also intra-species variations have been uncovered, for example plasticity in pattern formation in Acrobeloides nanus [21] and Diploscapter coronatus [27] or postembryonic mouth dimorphism in Pristionchus pacificus (clade 9; [28,29]). A high regulative potential was demonstrated by the hierarchy of somatic cell fate transformations after cell ablation in the early embryo of $A$. nanus (clade 11; [30]). Even more dramatic peculiarities are found in Enoplea. Asymmetric cleavages and distinct cell lineages are initially missing in clade 1B (Enoplus brevis, Pontonema vulgaris) and only a gut lineage is present [22,31]. Development of Tobrilus diversipapillatus (clade 1C) is characterized by a prominent coeloblastula [32], a developmental character thought to be absent in nematodes. Compared to C. elegans, Romanomermis culicivorax (clade 2C) displays major differences in the establishment of embryonic polarity, pattern formation, programming of somatic founders and cell lineage complexity [33,34]. Hence, embryonic development of nematodes is much more diverse than the essentially invariant development of C. elegans and its closer relatives indicates.

Although in the Enoplea, development is usually much slower than in C. elegans, and their embryos are less transparent, we performed an extended analysis of development in selected species of this poorly studied basal group. Additionally we studied development in more detail in those clades of Chromadorea where only limited embryonic data have been available so far (Figure 1a). With these results, we now can address to what extent (i) nematodes follow a common general developmental program to generate the body plan typical for this phylum and (ii) developmental differences can be related to phylogenetic position (that is whether specific points can be defined where during evolution certain characters first appeared). The question which type of early cleavage was followed by the last common ancestor of nematodes has been controversially discussed in the past $[35,36]$. Therefore, we explored the notion that a nematode species with invariant polyclonal lineages generated by a fixed set of founder cells, such as C. elegans may have evolved from an ancestor such as Enoplus with just a single monoclonal lineage and a predominantly variable early embryogenesis.

\section{Methods}

\section{Strains and culture}

The strains Acrobeloides maximus (DF5048), Acrobeloides nanus (ES501), Caenorhabditis brenneri (SB280), Caenorhabditis briggsae (AF16), Caenorhabditis elegans (N2), Choriorhabditis dudichi (SB122), Diploscapter sp. (JU359), Diploscapter coronatus (PDL0010), Halicephalobus gingivalis (JB128), Panagrolaimus sp. (JU765), Panagrolaimus superbus (DF5050), Plectus aquatilis (PDL0018), Plectus cf. sambesii (ES601), Pristionchulus pacificus (PS312), Protorhabditis sp. (DF5055), Protorhabditis sp. (JB122), Rhabditis belari (ES103), Rhabditis dolichura (ES101), Teratocephalus lirellus (JB049), Tylocephalus sp. (PDL1001), Zeldia punctata (PDL0003) are cultured at $23^{\circ} \mathrm{C}$ on minimal agar plates essentially as described in [26]. Gravid animals of Achromadora sp., Aphelenchus avenae, Bursaphelenchus seani, Ironus sp., Prionchulus sp., Tobrilus diversipapillatus, Tobrilus pellucidus and Tobrilus stefanskii are isolated from soil samples of various origins essentially as described in [21]. Romanomermis culicivorax, Romanomermis iyengari and Strelkovimermis spiculatus were kindly provided by Dr. Edward Platzer, University of California, Riverside, CA, USA. Trichuris muris was kindly provided by Dr. Heinz Mehlhorn, Heinrich-Heine University, Düsseldorf, Germany. Belonolaimus longicaudatus was analyzed in the laboratory of Dr. Ole Becker, University of California, Riverside, CA, USA. Some gravid Enoplus brevis were kindly provided by Dr. V. Malakhov, Moscow State University, Russia, others were isolated from salt marsh soil supplied by Dr. W. Armonies, AWI List, Germany. Additional strains were obtained from Paul de Ley and Jim Baldwin, University of California, Riverside, CA, USA; Marie-Anne Felix, University Jacques Monod, Paris, France; Wouter Houthoofd and Wim Bert, University of Ghent, Belgium; Walter Sudhaus, Freie Universität Berlin, Germany; and Ralf Sommer, MaxPlanck-Institute for Developmental Biology, Tübingen, Germany. 


\section{Cell nomenclature and cell fate assignments}

Projection of the C. elegans standard cell nomenclature $[9,37]$ onto other nematodes implies the presence of similar cell differentiation patterns, which is not necessarily true. Therefore, we apply neutral lineage names (S1-S4/S5, somatic founder cells; P1-P4/P5, germline). We use the standard nomenclature ( $\mathrm{AB}, \mathrm{MS}, \mathrm{C}, \mathrm{D})$ to indicate cell fates that correspond to those in C. elegans as described in [34]. In this species but not necessarily in other nematodes $\mathrm{S} 1=\mathrm{AB}, \mathrm{S} 2=\mathrm{EMS}, \mathrm{S} 3=\mathrm{C}, \mathrm{S} 4=$ D.

Although we traced cell divisions only up to a few hundred cells, we could assert the degree of variation from the pattern found in C. elegans (fixed lineages with unambiguous fate assignments). As we did not observe prominent rearrangements of cell clones after gastrulation we were able to assign fate categories ('AB'-like, 'S'like, and so on; Figure 1c) to each of the founder cells based on position, structure and behavior of their descendants [34]. These cell fate categories imply similarities to C. elegans in terms of cell types derived from this lineage (for example 'AB', generates at least the majority of neurons; 'S' contributes to the pharynx) but may differ in detail. 'E' stands exclusively for gut fate in all studied species.

\section{Microscopy}

With the exception of Enoplus (see below) 1-cell and 2cell stage embryos collected from culture plates or cut out of gravid adults were mounted on slides carrying a thin $3 \%$ agarose layer as a mechanical cushion. The cover slip was sealed with melted petroleum jelly. Embryonic development was studied with DIC optics using a $100 \times$ objective. Stacks of optical sections were digitally recorded at 30 to 60 second intervals and at $23^{\circ}$ $\mathrm{C}$ with a 4-D microscope (Zeiss, Axioscope 2 mot). 3-D tracing of cell behavior and generation of cell lineages were software-supported (Simi Biocell; Unterschleißheim, Germany) essentially as described in [34]. Due to a sticky surface Enoplus 1-cell stages adhered reliably to an untreated microscope slide. This was immersed into a petri dish filled with brackish water (ratio sea water to tap water, 2:1) and then covered with aluminum foil. Development was recorded on time lapse video tape with a $20 \times$ water immersion objective. Evaporated water was replaced daily. If not stated otherwise the development of at least three embryos per species has been analyzed.

\section{Results}

\section{Embryogenesis of Enoplus brevis}

We confirmed, with photo documentation, the observations of Russian researchers (see introduction). First cleavages are equal (Figure 2a1-a2) and lead to variable spatial arrangements. In the 8-cell stage one blastomere divides after a delay (Figure 2a3, black asterisk). This cell is the founder of the gut lineage. During gastrulation its two daughter cells are translocated into the interior of the embryo (Figure 2a4-a5) as in C. elegans.

\section{Embryogenesis of Tobrilus stefanskii}

While in the early E. brevis embryo, only a single fixed cell lineage exists [31], in Romanomermis culicivorax already six fixed lineages are present as in C. elegans even though with different fate assignments [34]. Searching for species occupying intermediate evolutionary steps between these two extremes, we analyzed early embryogenesis of the basal nematode Tobrilus stefanskii $(\mathrm{n}=11$; clade $1 \mathrm{C})$. With its early symmetric cleavages, the absence of visible cell lineages and its prominent coeloblastula, first described for another member of the genus [32], embryogenesis differs strikingly from C. elegans (clade 9A; [9]) and $R$. culicivorax (clade 2C; $[33,34])$.

T. stefanskii is a gonochoristic species with oviposition at the 1-cell stage preceding pronuclear fusion (Figure 2b1). The first division generates cells of equal size (Figure $2 \mathrm{~b} 2$ ). Both spindles in the 2-cell stage orient at right angles to the first division, following the 'centriolic principle' (that is during consecutive cleavages spindles form at right angles to each other due to changing positions of centrioles; $[38,39])$. We named this early cleavage pattern 'H-Type' (Figure 1b). The first two cell division rounds produce descendants of equal size (Figure 2b2b3). In the 4-cell stage various spatial arrangements are found $[22,32]$. Then the first asymmetric cleavages are observed. Based on these and subsequent asymmetries, and on specific cell behavior and lineage analysis described below, cells could be assigned lineage names in retrospect (for cell nomenclature, see materials and methods). One blastomere of the 4-cell stage shows the stem cell behavior and additional features typical for a germline cell in other nematodes (for example permanent contact with gut precursors; see below). Hence, we named it P2 and its sister S2. The remaining two cells are then daughters of S1. For better comparison with other species we named them S1a and S1p, although position relative to each other is variable. The nuclei in the cell cousins S1p and P2 leave their central position and become located side by side at the cell membrane (not shown). This is as found in R. culicivorax where, however, cell asymmetry starts to form already in the 2cell stage (Figure 2c1; [33]). With the onset of division, the forming mitotic spindles in S1p and P2 become oriented and asymmetrically displaced toward a common point (green square, Figure $2 \mathrm{~b} 3$ ). The orientation of these two spindles corresponds to the anterior-posterior ( $a-p)$ axis of the embryo. The resulting P3 is 


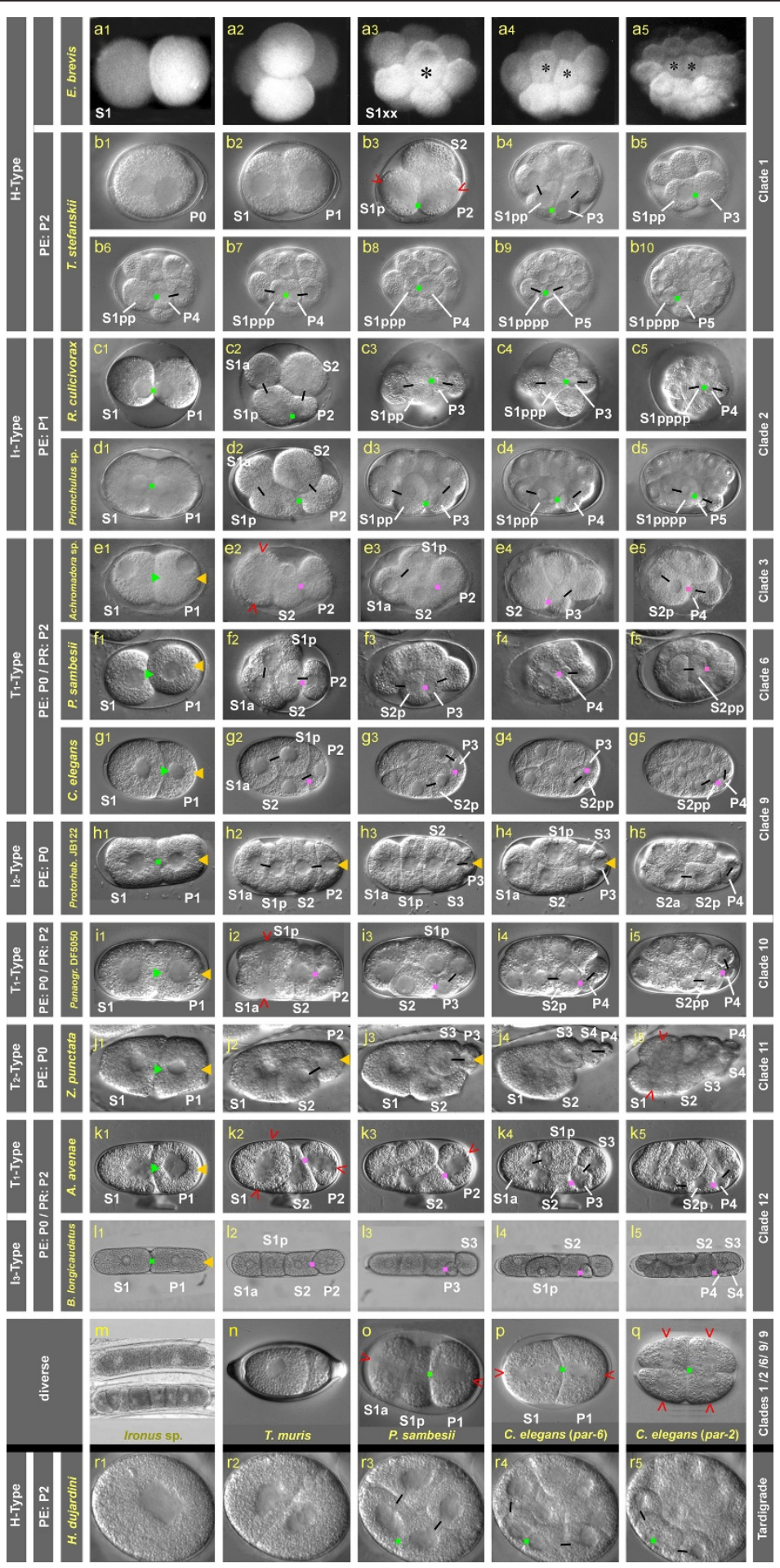

Figure 2 Cleavage and polarity. Early cleavage patterns in 12 nematode species (a-I) and the tardigrade Hybsibius dujardini (r). In addition, single images of selected nematode embryos are shown ( $\mathbf{m}-\mathbf{q})$. Representatives are ordered according to clades (right margin). On the left margin the type of early cleavage, stage when visible polarity is established (PE) and polarity reversal in the germline (PR) are indicated where applicable. Position and action of POCs deduced from cell behavior are marked. Green dot, primary POC acting on two adjacent cells; green arrowhead, primary POC acting on P1 only; purple dot, secondary POC acting on two adjacent cells; yellow arrowhead, tertiary POC, acting on germline cells; open red arrowhead, orientation of cleavage spindle; black bars connect sister cells. Figure $2 r$ was taken from [48] with permission from Elsevier; Figure 2q was taken from [67]. 


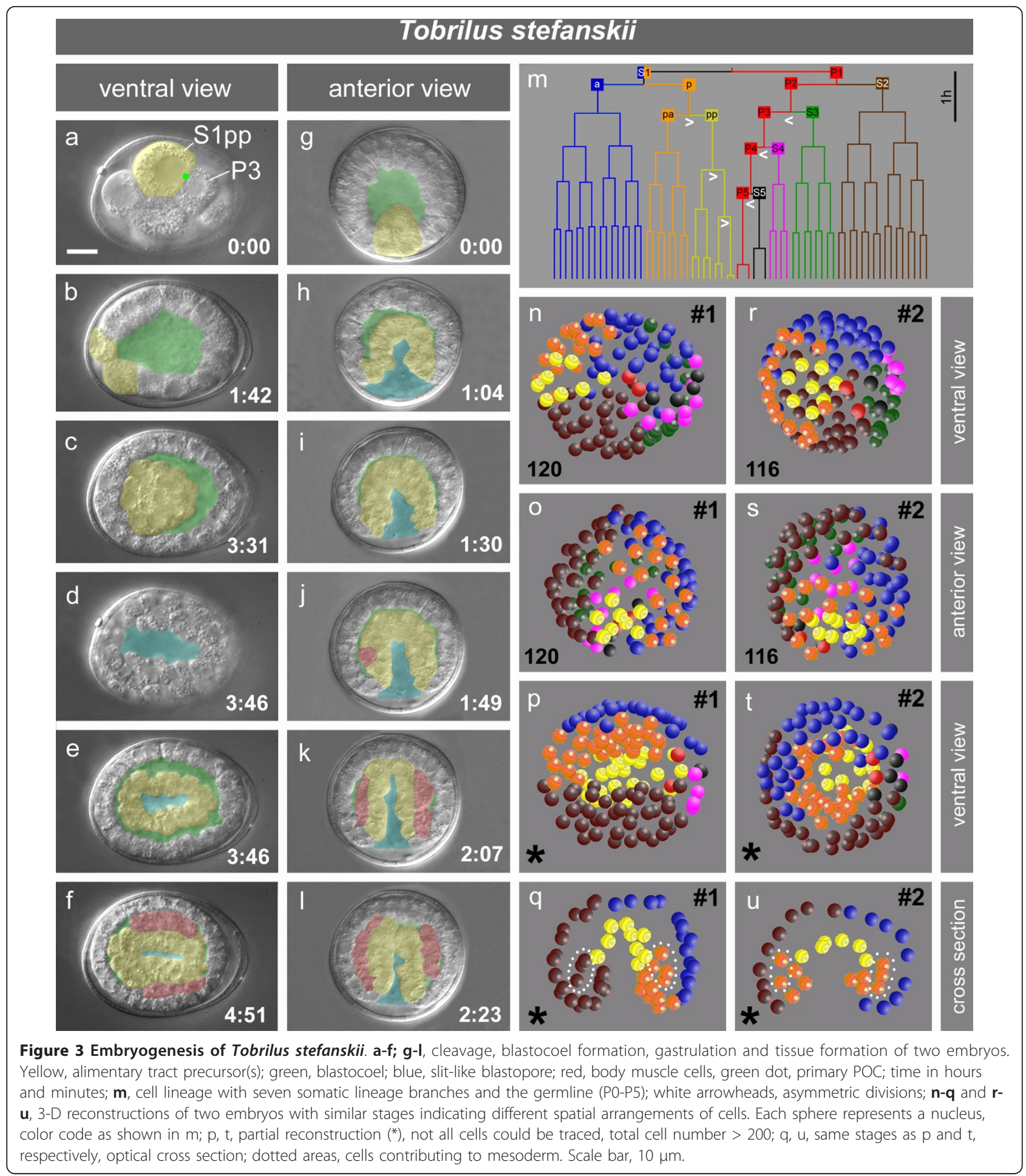

much smaller than its sibling S3, while size differences between S1pa and S1pp are less prominent (Figure 2b4).

The events described above are repeated when the cousins S1pp and P3 (Figure 2b4 to b6) and S1ppp and P4 (Figure $2 \mathrm{~b} 7$ to b9) cleave asymmetrically (marked in Figure $3 \mathrm{~m}$ ). Spindles in S1pppp and P5 are oriented along the a-p axis as well but the divisions of these cells are not obviously asymmetric. The soma/germline cell pairs named above remain firmly attached to each other and their mitotic spindle microtubules appear to find distinct anchorage sites in the area of cell attachment (Figure $2 \mathrm{~b} 3$ to b10) leading to a linear orientation of 
spindles. Consequently an array of cells forms along the future midline as a prerequisite for the establishment of bilateral symmetry (see paragraph below). This strongly resembles cell behavior in the early embryo of $R$. culicivorax (Figure 2c1 to c5; [33]) induced by the 'Region of First Midbody' (RFM). As we do not know whether the underlying mechanism is the same in both species we named it more generally 'Polarity Organizing Center' (POC). To distinguish it from other centers found in the higher-numbered clades (see below) we call it 'primary POC' (marked in green in Figures 2 to 5 ).

After having identified a germline, we traced the fate of the remaining cells. In the 8-cell stage S1pp and P3 are neighbors with nuclei asymmetrically positioned adjacent to the primary POC (Figure 3a), and both divide with delay (Figure $3 \mathrm{~m}$ ). S1pp turns out to give rise to the alimentary tract (that is gut+pharynx; Figure 3a to 3f). This is different from R. culicivorax [34] and Enoplus [31,40], where the founder cell for the alimentary tract is already present one cell generation earlier (Figure 1c). In Chromadorea the differences are more dramatic as there the gut is generated by S2p (Figure 1c and below; [7,9,21,22]).

As in other nematodes $[21,41]$ the germline in T. stefanskii remains in permanent contact with the gut founder and its descendants. In contrast to C. elegans, in $T$. stefanskii $\mathrm{P} 4$ performs another asymmetric division resulting in S5 and P5 (Figure 2b10). The latter behaves like $\mathrm{P} 4$ in C. elegans, in that it divides symmetrically. Its daughters follow the gut precursors into the center of the embryo (Figure 3p, t).

Typical for all three of the Tobrilus species we looked at, is the formation of a prominent coeloblastula (Figure $3 \mathrm{~b})$. They undergo a 'canonical' gastrulation, with the invagination of a layer of alimentary tract precursor cells (Figure 3c, g to j, $\mathrm{n}$ to $3 \mathrm{u}$; [32]). The blastocoel starts to form as early as the 4-cell stage and grows to its full size before the 100-cell stage. Gastrulation starts with the invagination of the eight S1pp descendants (Figure $3 \mathrm{~g}, \mathrm{o}, \mathrm{s})$. Other cell groups join them but their lineage origin varies among the analyzed embryos. As divisions continue, the immigrated cells fill the blastocoel (Figure $3 \mathrm{c}, \mathrm{g}$ to $3 \mathrm{i}$ ), leaving an oval-shaped blastopore furrow on the ventral side (Figure 3d) that reaches deep into the alimentary tract primordium (Figure 3k). Eventually it closes from the center in both directions along the a-p axis like a zipper, resulting in future mouth and anus at its ends (not shown) similar to R.culicivorax and other basal nematodes [22,34]. After immigration of future alimentary tract cells (leaving only small remnants of the blastocoel), body muscle precursors of various lineage origin move between these and the outer layer of cells (Figure 3f, $\mathrm{j}$ to $3 \mathrm{l}$ ).

Lineage analysis and 3-D reconstructions $(\mathrm{n}=9)$ revealed that in contrast to members of clade $1 \mathrm{~B}$ in the early $T$. stefanskii embryo, three distinct cell lineages can be defined (Figure 1c), for gut ('E'), pharynx ('S'; additional cells contribute variably to this organ) and germline ('P'). For the remainder no fixed correlation between lineage and fate exists, that is the spatial arrangement of these blastomeres and their contributions to tissues is variable. This is exemplified in the two embryos shown in Figure 3. In embryo \#1 (Figure 3p) descendants of S1pa (orange; left side) and S2 (brown; right side) form separate clones. Cells of both origins migrate in (Figure $3 \mathrm{q}$ ) to contribute to the mesoderm. In embryo \#2 (Figure 3t) S1pa descendants are located on both sides and at this stage cells between the inner and outer cell layer are all members of this lineage branch (Figure $3 \mathrm{u}$ ). Among the other specimens of T. stefanskii we found various combinations of S1a, S1p and S2 lineages contributing to body muscle cells.

\section{Embryogenesis of Prionchulus sp}

To narrow this gap between Tobrilus with three and Romanomermis with six lineages we studied a second representative of clade 2B, Prionchulus sp. (Mononchida, $\mathrm{n}=4$ ). In earlier studies contradictory conclusions had been drawn concerning the existence of early asymmetric cleavages and distinct cell lineages in this genus $[42,43]$.

We found several basic similarities to $R$. culicivorax (Figure 2c1 to c5; $[33,34]$ ) in that the first division in Prionchulus is symmetric, nuclei of the 2-cell stage occupy adjacent positions (Figures $2 \mathrm{~d} 1,4 \mathrm{~b}$ ), and both spindles become oriented along the a-p axis (Figure 4c to $4 \mathrm{~d}$ ). The latter indicates the action of a primary POC already in the 2-cell stage. We call this the 'I-Type' of cleavage. As it differs from similar I-Type cleavage patterns seen in higher-numbered clades (see below) we named it ' $\mathrm{I}_{1}$-Type (Figure 1b). In Prionchulus, S1p is definitely larger than S1a while size differences between S2 and P2 are less prominent (Figures 2d2, 4e). A similar pattern can be identified in (Longidorus elongatus Figure 1a; [44])

Restricted by the limited space in the eggshell, 4-cell stage blastomeres arrange themselves in two alternative rhomboid variants, whereby either S2 or P2 occupy a position adjacent to S1a (Figure 2d2, $n=2$; Figure $4 f, n$ $=2$ ). In both of these S1p and P2 touch each other and form lineally oriented spindles (Figure $4 \mathrm{f}$ ) resulting in daughter blastomeres arranged in tandem (Figure 2d3). The same process is repeated with the division of the cell pairs S1pp-P3 (Figures $2 \mathrm{~d} 3$ to d4, g to $4 \mathrm{~h}$ ) and S1ppp-P4 (Figures $2 \mathrm{~d} 4$ to $\mathrm{d} 5,4 \mathrm{~h}$ to $4 \mathrm{i}$ ). The fact that members of each pair do not move relative to each other underlines the continuous presence of a centrally located POC. 


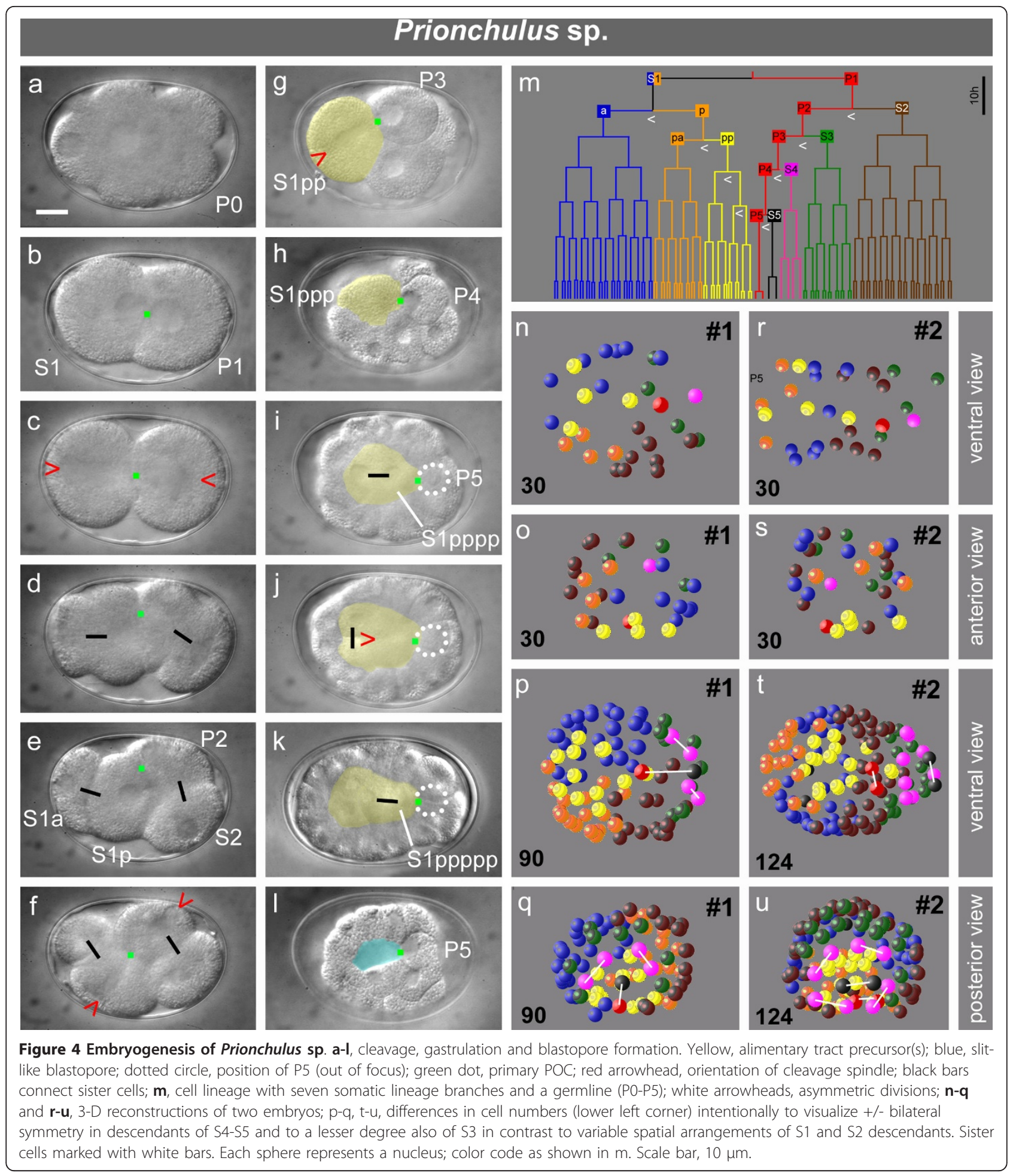

Gastrulation starts with the immigration of S1pppa +S1pppp in the absence of a coeloblastula (Figures 2d5, 4i). Descendants of S1ppa follow somewhat later and contribute to the pharynx. Thus, they show some resemblance to the behavior of MS (S2a) in C. elegans.
However, as we could not find any contribution to body muscles we marked their fate with ' $\mathrm{S}$ ' in Figure 1c. The same applies to Tobrilus (see above) and Romanomermis [34]. Contacts remain between P5, still positioned on the surface, and S1pppp and its posterior daughter 


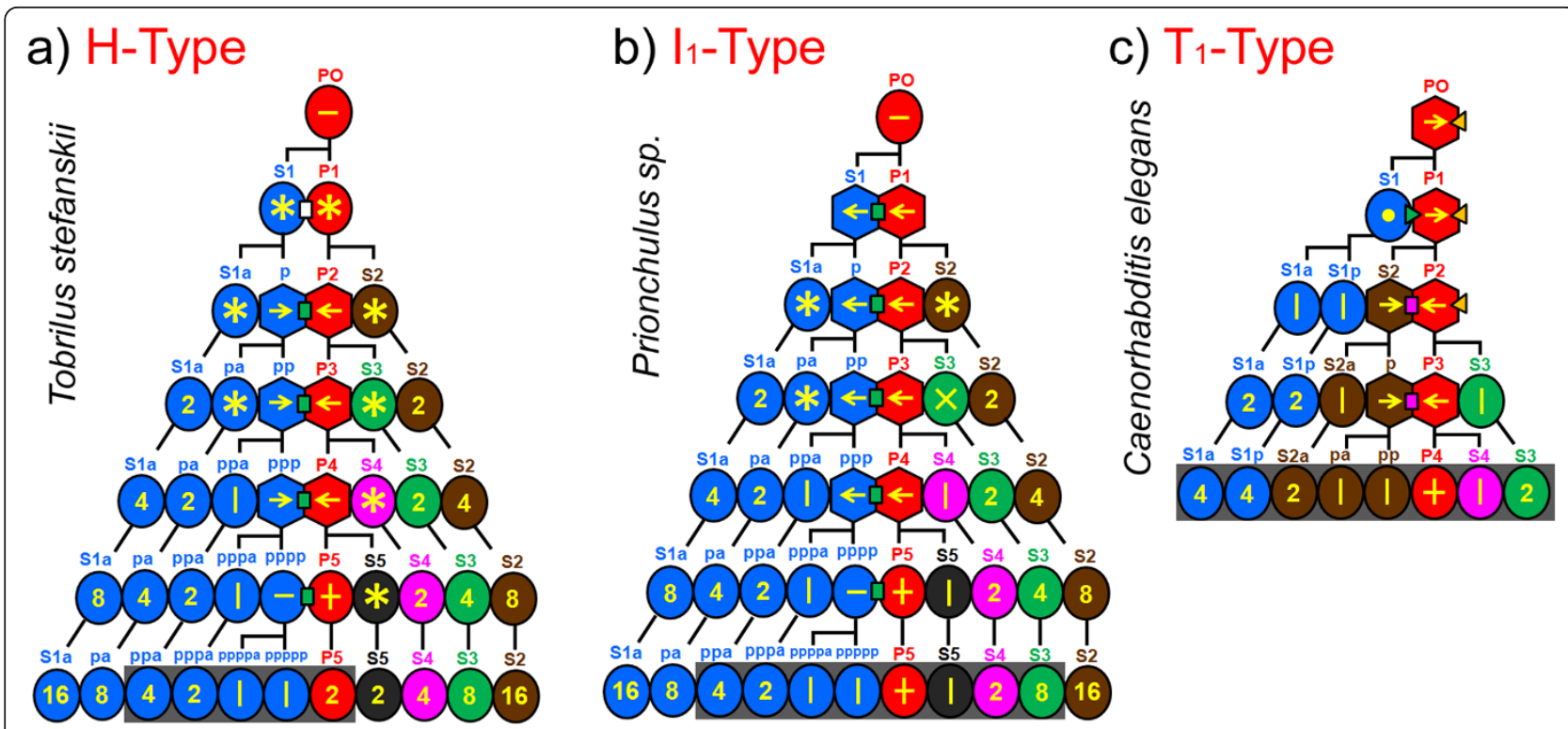

Figure 5 Early cleavage and model of POC action. a-c, Simplified early lineage trees of three nematode species with different cleavage types. A series of unequal cleavages attributed to the action of POCs results in cells arranged in tandem along the a-p axis. For symbols and color codes of POCs, see Figure 2. Note that cells performing I-r divisions belong to different generations. These cells or their descendants are shown in grey boxes to indicate lineage branches involved in the establishment of bilateral symmetry. Circles, blastomeres performing symmetric cleavages; hexagons, blastomeres performing asymmetric cleavages. Orientation of cleavage spindles: asterisk, variable; arrow, longitudinal, pointing toward smaller daughter cell; horizontal bar, longitudinal with daughters of equal size, vertical bar, left-right; circle, dorsal-ventral; ' $X$ ' somewhat variable generating imperfect symmetric clones; ' + ', germline cell giving rise to two mirror image gonadal arms in the anterior and posterior half of the adult.

S1ppppp (Figure 4i to 4k). Prionchulus shows high similarities to Tobrilus with respect to blastopore formation (Figure 5l) and the behavior of S1a, S1pa and S2 descendants. A further similarity, revealed by 3-D reconstructions of two embryos (Figure $4 n$ to $u$ ) is the considerable positional variability of blastomeres.

As in Tobrilus we could only identify lineages for the alimentary tract ('S' + 'E') and the germline ('P'). However, here additional cells (S3-S5) occupy essentially invariant positions. They participate in the formation of bilaterally symmetric structures (Figures 1c, 4 p, q, t, u; see below) and appear to contribute to body muscles and hypodermis roughly corresponding to the $C$ and $D$ lineages in C. elegans. Due to limited transparency we could not ascertain whether S3-S5 make fixed contributions to the developing embryo. In any case these differ from the pattern found in Romanomermis and in $C$. elegans.

Embryogenesis in Prionchulus is much slower than that in Tobrilus. Initially, in both species cell cycles of all blastomeres are close to synchronous. Later, descendants of P3 and S1pp divide more slowly than other blastomeres. This is more obvious in Tobrilus than in Prionchulus (Figures $3 \mathrm{~m}$ and $4 \mathrm{~m}$ ).

Our finding that cell lineages exist in the early Prionchulus embryo accords with the report of
Drozdovskiy [42], however, we did not find the Ascarislike invariant cleavage pattern with strict early bilateral symmetry and invariant cell positioning as shown in his sketches.

\section{Early embryogenesis in Chromadorea: 4 different cleavage types}

$T_{1}$-type, Clades 3, 4, 5, 6, 7, 8, 9A, 10, $12 A$ (Figure 1b, blue lineage branches)

In the standard C. elegans (clade 9A; Figure 2g1 to g5), the first division is unequal, generating a larger $\mathrm{S} 1$ and a smaller P1 cell. While AB divides with transverse spindle orientation (following the centriolic principle; see above) P1 reorients its spindle to divide into a larger anterior S2 and a smaller posterior P2 (Figure 2g1 to g2). We named this early cleavage pattern 'T-typ'. In P2 a reversal of cleavage polarity (PR) takes place [41]. To distinguish this cleavage pattern we call it ' $\mathrm{T}_{1}$-type'.

In Achromadora (clade 3; Figure 2e1 to e5), the first division is more or less equal in size (Figure 2e1) otherwise early cell behavior is similar to C. elegans. Our limited observations in representatives of clades 4 and 5 (Desmodorida and Monhysterida) correspond well with descriptions by Malakhov [22] and make clear that, like C. elegans, early cleavages follow the $\mathrm{T}_{1}$-type pattern (data not shown). The same is true for species of clade 
6 (Plectus; Figure $2 \mathrm{f} 1$ to 55 and Tylocephalus; [26]), clade 7 (Teratocephalus; [26]), clade 8 (Ascaris; [7]), clade 10 (Panagrolaimus; Figure 2i1 to i5) and clade 12A (Aphelenchus; Figure $2 \mathrm{k} 1-\mathrm{k} 5)$. A slight variation of the $\mathrm{T}_{1}$-type cleavage pattern (green lineage branches) was detected in two representatives of the genus Rhabditis, where PR was found in either P2 or P3 [45].

\section{$I_{2}$-type, Clade $9 B$ (Figure 1b, red lineage branches)}

More prominent is a modification found in clade $9 \mathrm{~B}$ with the genera Protorhabditis (Figure $2 \mathrm{~h} 1$ to h5) and Diploscapter [27]. There, both first blastomeres divide with a-p oriented spindles resulting in a tandem arrangement of blastomeres [14] resembling the $\mathrm{I}_{1}$-type cleavage pattern found in Romanomermis and Prionchulus (Figures $2 \mathrm{c} 1$ to $\mathrm{c} 5$; $\mathrm{d} 1$ to $\mathrm{d} 5$ ). The elongate eggshell allows a strictly linear order of blastomeres after the divisions of S1, P1 and P2 (Figure 2h2, h3). The germline cells, due to the absence of PR, end up occupying positions posterior to their somatic sisters. To establish the $d-v$ axis and to reach the typical neighborhood between the primordial germ cell $\mathrm{P} 4$ and the gut precursor S2p, prominent rearrangements ('cell sorting'; Figure 1c) are required (Figure $2 \mathrm{~h} 3$ to h5) as described for $D$. coronatus [27].

$T_{2}$-type, Clade 11 (Figure 1, purple lineage branches) Acrobeloides nanus [21] and Zeldia punctata (Figure 2 j1-j5) follow the T-type of cleavage; however, in contrast to the $\mathrm{T}_{1}$-type $\mathrm{PR}$ is absent and therefore germline cells occupy the most posterior positions. Consequently, cell rearrangements among P2 descendants are required to reach a C. elegans-like pattern prior to the onset of gastrulation as described above for the ' $I_{2}$-type'.

$I_{3}$-type, Clade 12 (Figure 1, pink lineage branches)

Belonolaimus longicaudatus (Figure 211 to 15 ) and Meloidogyne incognita [14] follow the I-Type of cleavage. However, this differs from the two 'I-types' introduced above (PR in P1 or absent) in that PR takes place in $\mathrm{P} 2$.

In summary, in nematodes we found six different early cleavage patterns, two among Enoplea and four among Chromadorea. In the phylogenetic tree (Figure 1a) $\mathrm{I}_{2-}$, $\mathrm{T}_{2^{-}}$and $\mathrm{I}_{3}$-types are restricted to distinct branches indicating they are apomorphic modifications of the prevalent $\mathrm{T}_{1}$-type.

\section{The POC, a general developmental principle in nematodes?}

Having detected the action of a POC in three representatives of Enoplea we wanted to determine whether such a mechanism is also characteristic for early embryogenesis of Chromadorea and thus may constitute a general developmental principle in nematodes.

In contrast to Tobrilus, Prionchulus and Romanomermis, three POCs can be defined in C. elegans which are involved in longitudinal spindle orientation and serial arrangement of founder cells. Laser ablation experiments in 2-cell embryos revealed a microtubule-pulling force at the anterior pole of P1 [46]. Located in the RFM, it resembles the 'primary POC' described above, although normally it only acts in P1 (Figure 2g1; green arrowhead). However, in embryos with defects in the expression of par genes, spindle orientations in P1 and $\mathrm{S} 1$ are altered (Figure 2p, q), suggesting an interaction between PAR proteins and the primary POC (see discussion). Another POC ('secondary POC'; marked in purple in Figure 2) positioned in the 'region of the second midbody' (RSM), initially orients spindles in the two sister cells $\mathrm{S} 2$ and P2 and subsequently in the cell cousins $\mathrm{S} 2 \mathrm{p}+\mathrm{P} 3$ and $\mathrm{S} 2 \mathrm{pp}+\mathrm{P} 4$ (Figure $2 \mathrm{~g} 2$ to g5). This differs from the situation in Enoplea described above where S1, not S2, descendants are involved. For C. elegans it has been shown that the polarizing function of the secondary POC depends on the presence of MES-1/ SRC-1 proteins (see discussion). A third POC ('tertiary POC'; marked in yellow in Figure 2) is established at the posterior pole of the 1-cell stage as a consequence of sperm entry [47]. It polarizes the fertilized egg, is crucial for asymmetric divisions of germline cells and depends on the polar distribution of PAR proteins (Figure 5c; see discussion).

As the majority of Chromadorea studied follow the $\mathrm{T}_{1}$-type of cleavage (Figure 1a; blue branches; Figure 2e to $2 \mathrm{~g}, \mathrm{i}, \mathrm{k}$ ) and early cell behavior is very similar to $C$. elegans, it indicates the activity of all three POC types. The other cleavage types (Figure 1b) can be explained with an altered expression pattern of PAR proteins affecting the function of the primary POC and the presence or absence of a PR in the germline (Figures 2, 5 and discussion).

\section{POC-based establishment of polarity beyond nematodes?}

Our studies on early embryogenesis in nematodes revealed a characteristic cleavage pattern where, through several cell generations, two blastomeres orient their spindles towards a POC resulting in a series of asymmetric cleavages (Figure 2). We wondered whether this pattern is unique for nematodes and therefore compared it to early development of the tardigrade Hybsibius dujardini studied by Gabriel et al. [48]. According to the Ecdysozoa hypothesis [49] tardigrades are a sister group of nematodes. We found that early development of Hybsibius shows unexpected similarities to Tobrilus (Figure 2b). The first two divisions are equal with subsequent spindles perpendicular to each other (Figure 2r1 to $\mathrm{r} 3$ ), typical for the 'H-Type' of cleavage (Figure 1b). Then, tandem orientation of spindles in two neighboring cell cousins and subsequent asymmetric divisions indicate the presence of a POC (Figure 2r3, r4). As in 
Tobrilus, two adjacent cell cousins perform asymmetric, longitudinally oriented cleavages (Figure 2r5). Thus, a distinct POC-controlled division pattern is obviously shared between nematodes of clade $1 \mathrm{C}$ and at least one representative of tardigrades. In a species belonging to a different branch of tardigrades the H-type of early cleavage was observed, too, but not the reproducible unequal divisions [50].

\section{Establishment of bilateral symmetry}

We found that despite considerable differences with respect to early development (for example $\mathrm{H}-$, I-, Tcleavage types; PR in P1, P2, P3 or absent; Figures 1b, 2, $3 \mathrm{~m}, 4 \mathrm{~m}, 5)$, in all studied embryos with the exception of Enoplus (clade 1B; Figure 2a), a linear sequence of cells with different fates is generated along the a-p body axis due to the action of one or more POCs. Some or all of these divide into left and right descendants with equivalent fates on both sides of the midline. This way bilateral symmetry is established within individual cell lineages. To determine to what extent nematodes with different cleavage patterns vary in the way they develop bilateral symmetry, we compared early pattern formation in all 12 clades (Figure 1). Three representative species for the H-, I-, and T-types are shown in Figure 5.

In T. stefanskii (Figure 5a) a visible polarity is established in the 4cell stage (see above) and descendants of S1p and P2-P5 are aligned along the future midline. However, only three somatic cells (S1pppa, S1ppppa, S1ppppp) perform left-right oriented cleavages resulting in bilateral symmetric clones. Adhering to the centriolic principle (see above) the remaining blastomeres divide with variable spindle orientations giving rise to clones with indeterminate spatial positions.

In Prionchulus sp. (Figure 5b) in addition to three descendants of S1p also S4 and S5 execute divisions with transverse spindle orientation and subsequently generate bilaterally symmetric clones. S3 divides with oblique spindle orientation forming an imperfect early l-r symmetry (Figure $4 \mathrm{p}$ to $4 \mathrm{u}$ ). The other cells show variable arrangements.

Thus, in Tobrilus and Prionchulus part of bilateral body symmetry must be established later, probably in a position-dependent manner as a result of cell-cell interactions.

In contrast, in C. elegans (Figure 5c) and all other studied members of clades $2 \mathrm{C}-12$ all somatic founder cells or their early descendants form bilaterally symmetric clones (for modification of this principle in S1a cells, see [9]), independent of whether they follow the $\mathrm{T}_{1}$-(Figure $5 \mathrm{c}), \mathrm{T}_{2^{-}}, \mathrm{I}_{2^{-}}$(Figure $5 \mathrm{~d}$ ) or $\mathrm{I}_{3}$-type of cleavage.

Comparing the three examples shown in Figure 5 a tendency can be observed towards an earlier and complete fixation of bilateral symmetry. The start of asymmetric divisions shifts from the 4-cell stage (Tobrilus) to the 1-cell stage (C. elegans) while the number of cell generations needed to perform all the l-r divisions described above decreases from seven (Tobrilus) to five (C. elegans) and the number of somatic lineages involved in early symmetry formation (Figure 1c) increases from two (Tobrilus) to five (C. elegans).

\section{Differences and similarities during ongoing embryogenesis}

Our study makes clear that early embryogenesis differs dramatically among species, particularly within Enoplea. In addition, tissue formation varies during later stages. In a previous publication we showed that hypodermis is generated in Romanomermis very differently from that in C. elegans [34]. Preliminary data indicate that hypodermis formation in Prionchulus does not follow the pattern found in Romanomermis, in spite of both being members of the same clade. The peculiarities of gastrulation in Tobrilus (Figure 3) including the way cells assemble to form the gut are not only different compared to C. elegans but also to Enoplus (see above). We also found indications that founder cells contribute differently to the pharynx $[9,34]$ and how this organ is formed (data not shown). However, eventually all variants seem to merge into a common pattern. The process of transforming a ball of cells consisting of three germ layers into an elongated worm during the "morphogenesis phase" starts with a ventral indentation separating head and tail regions in all studied nematodes. The progressive elongation of the embryo looks similar to C. elegans [51], although the degree of elongation varies considerably (that is juveniles may be longer and thinner). From this we conclude that the developmental constraints during the second half of embryogenesis are higher than during the early phase.

\section{Discussion}

In this paper representatives of all 12 nematode clades (according to the phylogeny by [5]) have been compared with respect to their early embryogenesis. Our data document that the very similar and reproducible development found in the reference systems Ascaris and $C$. elegans (see introduction) exemplifies only one of many ways to generate a nematode worm from a 1-cell embryo. They indicate that the cleavage and differentiation program of blastomeres diverged dramatically during evolution. This is particularly obvious in Enoplia (clade 1) and Dorylaimia (clade 2). In each of these taxa developmental peculiarities and variations appear to be higher than in all Chromadorea (clades 3 to 12) combined. Because of distinct developmental features (Figures $1 \mathrm{~b}, 2$ to 5) it appears reasonable to break down clades 1, 2, 9 and 12 into subgroups (Figure 1a). 
We believe that major developmental characters found in Enoplea but absent in Chromadorea (clades 3 to 12; Figures 1,2) are plesiomorphic. These include the 'canonical' gastrulation in the genus Tobrilus with its large blastocoel (Figure 3; [32]) found in many other animal phyla including Nematomorpha (our unpublished results), the nearest phylogenetic neighbors of nematodes, and the similarity of early cleavage patterns between Tobrilus (Figure 2b) and the tardigrade Hybsibius (Figure 2r) which according to the Ecdysozoa hypothesis [49] belongs to a neighboring phylum. Thus, our findings support the positioning of Enoplea close to the base of the phylogenetic tree of nematodes postulated on grounds of molecular sequence data $[2,5,6]$. This implies that the route of lineage evolution went from an S1 to an S2 origin of the gut (Figure 1c; $[22,40])$, which required considerable modifications in cleavage pattern and fate assignment [34]. Furthermore, comparison of embryogenesis between nematodes, nematomorphs and tardigrades suggests that certain features (for example the absence of initial asymmetric cleavages) were shared by their last common ancestor.

\section{Variations, evolutionary trends and developmental system drift}

Our data including those on Romanomermis (clade 2C) indicate a boost in lineage complexity, that is a stepwise increase from a single to five somatic lineages (Figures $1 c, 5)$ and a change from a monoclonal to a polyclonal fate assignment [34]. This change, which appears to have coincided with the transition from Enoplea to Chromadorea (Figure 1), is correlated with an increase in early fate decisions, which in turn reduces the amount of cell migration necessary for proper tissue formation $[12,34,52]$.

Comparing embryogenesis of representatives along the nematode phylogenetic tree (Figure 1a) we find that intra-species variation of early cell patterns decreases due to an increase of founder cells that generate descendants occupying fixed positions. Hence, our data are in favor of the conception that invariant development following distinct lineage programs is a derived and not an original feature (see introduction).

From the degree of individual variation within a species we can deduce how strongly fixed the developmental program must be and thus how a change in cleavage type (Figure 1b) may have been established during evolution. In Plectus (clade 6) we observed rare cases $(2 /<$ 100 embryos) where S1 cleaved with longitudinal (Figure 2o) rather than transverse spindle orientation (Figure $2 f 2$ ), meaning a switch from a $T_{1}$ - to an $I_{2}$-cleavage type. As this deviation was found to be compatible with normal embryogenesis it demonstrates that the developmental program must possess a sufficient degree of plasticity to allow the disregard of the 'centriolic principle' (see results section). Such an embryo must potentially cope with altered segregation of cytoplasmic components and changes in relative cell positions which in turn may affect inductive signaling. In addition, our observation suggests that the change from one to another cleavage type started with a modification that was initially rare in the population.

The divergence of developmental pathways without corresponding changes in the emerging phenotype ('developmental system drift'; [53]) seems to be a widely spread phenomenon in the animal kingdom. The present study gives additional examples for this. Moreover, it indicates that embryogenesis in nematodes includes general distinctive steps that need to be taken. However, cellular events leading to these are not conserved among species suggesting that evolutionary constraints have been low on cell behavior but high not only on structure and function of the juvenile but also on intermediate embryonic stopovers. Two examples may suffice to put our idea across. (i) The contact beween gut and germline (a critical feature in many systems; [54]) can be achieved via PR in either P1, P2 or P3 or alternatively via 'cell sorting' in species where PR is absent. (ii) Cell fate assignment can be reached in the absence of a fixed early cleavage program or alternatively via monoclonal or polyclonal cell lineages. Recent findings by Lin et al. [19] show that a similar relationship can be found between cells and molecules. In two closely related nematode species behavior of early blastomeres with alternative fates is identical while the underlying signaling network differs.

The enormous differences in genomes among even closely related species [55] in contrast to the conserved morphology indicate a particularly relaxed relationship between genotype and phenotype in nematodes. This discrepancy can be attributed to the special construction of nematodes including a single chamber hydroskeleton which allows adaptation to very diverse habitats but leaves little room for modifications of the body plan.

\section{Polarity organizing centers (POCs) and embryonic pattern formation}

One of our central findings is the general presence of one or more POCs in early nematode embryos. While in the Enoplea Romanomermis [33], Tobrilus and Prionchulus (Figures $2 \mathrm{~b}$ to $2 \mathrm{~d}$; $5 \mathrm{a}$ to $5 \mathrm{~b}$ ) we found evidence that early embryogenesis involves just a single (primary) POC, in Chromadorea up to three (primary, secondary and tertiary) POCs appear to be active in organizing orientation and asymmetry of divisions. Only for C. elegans do we have information about the molecular basis of the secondary and tertiary POC. 
Laser ablation experiments in C. elegans [46] revealed a 'cortical pulling site' at the anterior pole of P1. Observations by Keating and White [56] support the view that the midbody between $\mathrm{AB}$ and $\mathrm{P} 1$ specifies a region of the cortex that directs rotational alignment of the centrosome-nucleus complex. This region of the first midbody (RFM; [33]) corresponds to our primary POC.

Most prominent is the activity of the tertiary POC at the posterior pole. Sperm entry initiates asymmetric distribution of PAR and LET-99 proteins [47,57-60] and subsequently anterior-posterior (a-p)-oriented spindles and asymmetric divisions in the germline $[61,62]$. However, in a member of clade 11 (Figure $1 \mathrm{~A}$ ) axis polarity was found to be independent of the sperm entry point [63].

Mutants and RNAi phenotypes of $p k c-3$, par-2, par-3 and par- 6 in C. elegans demonstrate that a knockout of any of these genes changes the orientation of the cleavage spindle in the 2-cell stage and this way leads from the T-type to $\mathrm{H}$ - or I-types of cleavage (Figure $2 \mathrm{p}, \mathrm{q}$ ), even though followed by abnormal development [64-68].

To explain the different cleavage types in Chromadorea we propose that in contrast to Enoplea (where the primary POC always induces a-p spindle orientation in two adjacent cells; Figures $2 \mathrm{~b}$ to d, $5 \mathrm{a}, \mathrm{b}$ ), the polarizing function in Chromadorea is controlled by PAR proteins [27]. This view is supported by mutations and RNAi experiments in C. elegans leading to abnormal cleavage patterns. The par-2/par-3 double mutant follows the Itype of cleavage, demonstrating that neither of these genes is required for longitudinal orientation of cleavage spindles [64]. According to our model the prevalent Ttype (Figure 1b) can be explained with the anterior PAR complex suppressing the activity of the primary POC in S1. At the same time it gives a simple explanation why uniform distribution of anterior PAR proteins (after knockout of par-2) results in transverse spindle orientation in S1 and P1 (H-type; Figure 2q) and uniform distribution of posterior PAR proteins (after knockout of anterior par genes) leads to longitudinal spindle orientation in both cells (I-type; Figure 2p).

In C. elegans PAR proteins switch function after the 4cell stage has been reached and are involved in the establishment of apical-basal polarity [69]. Instead the MES-1/SRC-1 system is required to continue a-p polarization of blastomeres [70-72] and to induce the reversal of cleavage polarity (PR) in P2 [41] as is the case in the $\mathrm{T}_{1}$ - and $\mathrm{I}_{3}$-cleavage types (Figures $1 \mathrm{~b}, 2$ ). The expression domain of MES-1/SRC-1 corresponds to our secondary POC. Berkowitz and Strome [72] suggested that species without PR may have lost the MES-1/SRC-1 system (accordingly a secondary POC is not indicated in Figure $2 \mathrm{~h}, \mathrm{j})$. However, the question then remains how a-p divisions in the germline can be maintained in the $\mathrm{I}_{2}$ - and
$\mathrm{T}_{2}$-types. A straightforward explanation could be a prolonged activity of posterior PAR proteins. Indeed, in Protorhabditis (clade 9B, Figure 2h) an extended posterior expression of PAR-1 in the germline was observed by Brauchle et al. [18].

The peculiarities of early development in those Enoplea that we followed in some detail (Figure 2a to d) gave no indications that par genes are involved in cell polarization along the a-p axis as found in C. elegans. Although it would appear that this function may have been newly acquired in Chromadorea, our fragmentary data from two other Enoplida indicate that the situation is less clear. Trichuris muris (clade 2A) performs an extremely asymmetric first division (Figure 2n; see also [22]), and in Ironus (clade 1A) three consecutive longitudinally oriented cleavages result in a tandem of eight cells (Figure $2 \mathrm{~m}$ ). Both patterns cannot be readily explained with the activity of a primary POC alone. As our preliminary analysis of the $R$. culicivorax (clade 2C) genome indicates that par genes are present it remains to be determined whether at least in some Enoplea they may play a role in establishing the primary body axis.

Consecutive asymmetric divisions following a POClike principle are not restricted to invertebrates like nematodes and tardigrades but have been described for posterior blastomeres of the ascidian embryo as well [73]. In equivalent cells in the left and right half of the bilaterally symmetric embryo asymmetric positioning of cleavage spindles is induced by centrosome attracting bodies (CAB; $[74,75])$. The CAB contains proteins that are homologous to the anterior PAR proteins in C. elegans [76]. It remains to be determined whether this asymmetry generating mechanism can be traced back to the last common ancestor or has been acquired independently in all three taxa.

\section{Midline formation and bilateral symmetry}

A bilaterally symmetric body is typical for all higher animals. For C. elegans it has been shown that this symmetry is generated early within individual lineages [9]. The construction of a bilateral body plan requires the presence of a midline, separating left from right. Our studies revealed that in all analyzed nematodes, except clade $1 \mathrm{~B}$, such a midline can be defined during early embryogenesis.

In contrast to the models proposed by Meinhardt [77] for planarians, insects and vertebrates, in nematodes bilateral symmetry is generated in a surprisingly simple way. Due to the actions of one or more POCs (described above) which cause longitudinal spindle orientations and cleavage asymmetries over consecutive rounds of division, an array of cells is formed along the a-p axis. Depending on the species, part or all of these divide into left and right daughters (Figure 5) from which 
bilaterally symmetric clones arise. It appears likely that such a strategy requires specific conditions, for example a low number of blastomeres and their early specification on a single cell basis, features typical for nematodes.

\section{Cell lineage and cell specification}

The case of $C$. elegans demonstrates that even in a system with essentially invariant development and complex polyclonal lineages, inductive interactions are an integral part of the developmental program which requires specific cell contacts during narrow time windows [78-81]. The different early cleavage patterns described above (Figures 1b, 2) result in different cell neighborhoods. Either changes in cell contacts did not pose a problem during nematode evolution because interactions like those in C. elegans did not exist yet, or the network of interactions was adjusted simultaneously. Our data are in accordance with a stepwise establishment of such interactions going along with increasing invariance of cell positions. Experimental interference like recombining blastomeres $[70,82]$ in basal representatives could give us a better idea to what extent the pattern and relevance of embryonic inductions changed during evolution. Analysis of cell-specification patterns and their molecular underpinnings, particularly in Enoplea, should help to discern between two alternative visions. (i) Inductive interactions in early nematode embryos are historic remnants. They reach back to times when fixed lineages where mainly absent (for example Enoplus; [31]) or only simple, monoclonal lineages existed (for example Romanomermis; [34]) and were required for diversification of cell fate. (ii) Alternatively, they are more recent acquisitions made possible after fixed lineages assured invariant cell neighborhoods.

\section{Conclusions}

Nematodes are suitable objects to study evolution of development because species from all branches of the phylogenetic tree can be analyzed, embryos develop outside the mothers and most of them are transparent enough to perform cellular analysis in vivo. Our findings that early embryogenesis varies considerably among species indicates that constraints are high on the preservation of crucial developmental steps but not on cellular behavior leading to these. We argue that the direction of evolution went from indeterminate early cleavage without initial polarity to invariant development with establishment of polarity before division of the zygote. The observed action of a primary POC gives a clue how polarity in certain nematodes and other related taxa like tardigrades can be established in a way that differs from C. elegans, that is independent of the sperm entry point.

\section{Abbreviations}

CAB: centrosome attracting bodies; POC: polarity organizing center; PR: reversal of cleavage polarity in the germline; RFM: region of first midbody; RSM: region of second midbody.

\section{Acknowledgements}

We are indebted to various colleagues for sharing strains (listed in materials and methods) and to Vladimir Malakhov for introduction into enoplid development and Oleksandr Holovachov for identification of $P$. cf. sambesii. We thank Bob Goldstein for Figure 2r, July Ahringer for Figure 2q and Jay Burr for thoughtful comments on the manuscript. IS was supported by a grant of the Deutsche Forschungsgemeinschaft (Schi 214/16-1).

\section{Authors' contributions}

Both authors contributed to the conception and design of the study, were involved in acquisition of data, its analysis and interpretation. Both authors drafted the manuscript and read and approved the final version.

\section{Competing interests}

The authors declare that they have no competing interests.

Received: 22 July 2011 Accepted: 20 September 2011

Published: 20 September 2011

\section{References}

1. Blaxter ML, De Ley P, Garey JR, Liu LX, Scheldeman P, Vierstraete A, Vanfleteren JR, Mackey LY, Dorris M, Frisse LM, Vida JT, Thomas WK: A molecular evolutionary framework for the phylum Nematoda. Nature 1998, 392:71-75.

2. De Ley P, Blaxter ML: Systematic Position and Phylogeny. In The Biology of Nematodes. Edited by: Lee DL. Taylor and Francis, London; 2002:1-30.

3. Meldal BH, Debenham NJ, De Ley P, De Ley IT, Vanfleteren JR, Vierstraete AR, Bert W, Borgonie G, Moens T, Tyler PA, Austen MC, Blaxter ML, Rogers AD, Lambshead PJ: An improved molecular phylogeny of the Nematoda with special emphasis on marine taxa. Mol Phylogenet Evol 2007, 42:622-636.

4. Kiontke K, Barriere A, Kolotuev I, Podbilewicz B, Sommer R, Fitch DH, Felix MA: Trends, stasis, and drift in the evolution of nematode vulva development. Curr Biol 2007, 17:1925-1937.

5. Holterman $M$, van der Wurff $A$, van den Elsen $S$, van Megen $H$, Bongers $T$, Holovachov O, Bakker J, Helder J: Phylum-wide analysis of SSU rDNA reveals deep phylogenetic relationships among nematodes and accelerated evolution toward crown clades. Mol Biol Evol 2006, 23:1792-1800.

6. Aleshin W, Kedrova OS, Milyutina IA, Vladychenskaya NS, Petrov NB: Relationships among nematodes based on the analysis of $18 \mathrm{~S}$ rRNA gene sequences: molecular evidence for monophyly of Chromadorian and Secernentean nematodes. Russ J Nematol 1998, 6:175-184.

7. Boveri T: Die Entwicklung von Ascaris megalocephala mit besonderer Rücksicht auf die Kernverhältnisse [in German]. Festschrift für Carl von Kupffer Gustav Fischer Verlag, Jena; 1899, 383-430.

8. Müller $\mathrm{H}$ : Beitrag zur Embryonalentwicklung von Ascaris megalocephala [in German]. Zoologica 1903, 17:1-30.

9. Sulston JE, Schierenberg E, White JG, Thomson JN: The embryonic cell lineage of the nematode Caenorhabditis elegans. Dev Biol 1983, 100:64-119.

10. Schnabel $R$, Hutter $H$, Moerman D, Schnabel H: Assessing normal embryogenesis in Caenorhabditis elegans using a 4D microscope: variability of development and regional specification. Dev Biol 1997 184:234-265.

11. Houthoofd W, Borgonie G: The embryonic cell lineage of the nematode Halicephalobus gingivalis (Nematoda: Cephalobina: Panagrolaimoidea). Nematology 2007, 9:573-584.

12. Houthoofd W, Jacobsen K, Mertens C, Vangestel S, Coomans A, Borgonie G: Embryonic cell lineage of the marine nematode Pellioditis marina. Dev Biol 2003, 258:57-69.

13. Houthoofd W, Willems M, Jacobsen K, Coomans A, Borgonie G: The embryonic cell lineage of the nematode Rhabditophanes sp. Int J Dev Biol 2008, 52:963-967. 
14. Dolinski C, Baldwin JG, Thomas WK: Comparative survey of early embryogenesis of Secernentea (Nematoda), with phylogenetic implications. Can J Zool 2001, 79:82-94.

15. Vangestel S, Houthoofd W, Bert W, Borgonie G: The early embryonic development of the satellite organism Pristionchus pacificus: differences and similarities with Caenorhabditis elegans. Nematology 2008, 10:301-312.

16. Zhao Z, Boyle TJ, Bao Z, Murray Jl, Mericle B, Waterston RH: Comparative analysis of embryonic cell lineage between Caenorhabditis briggsae and Caenorhabditis elegans. Dev Biol 2008, 314:93-99.

17. Sommer RJ: Evolution of development in nematodes related to $C$. elegans. WormBook 'The C. elegans Resarch Community'; 2005 [http://www. wormbook.org].

18. Brauchle M, Kiontke K, MacMenamin P, Fitch DH, Piano F: Evolution of early embryogenesis in rhabditid nematodes. Dev Biol 2009, 335:253-262.

19. Lin KT, Broitman-Maduro G, Hung WW, Cervantes S, Maduro MF: Knockdown of SKN-1 and the Wnt effector TCF/POP-1 reveals differences in endomesoderm specification in C. briggsae as compared with C. elegans. Dev Biol 2009, 325:296-306.

20. Bolker JA: Model systems in developmental biology. Bioessays 1995, 17:451-455.

21. Skiba F, Schierenberg E: Cell lineages, developmental timing, and spatial pattern formation in embryos of free-living soil nematodes. Dev Biol 1992, 151:597-610

22. Malakhov W: Nematodes Structure, Development, Classification and Phylogeny. Washington Smithsonian Institution Press; 1994.

23. Voronov DA: The embryonic development of Pontonema vulgare (Enoplida: Oncholaimidae) with a discussion of nematode phylogeny. Russ J Nematol 1999, 7:105-114.

24. Goldstein B: On the evolution of early development in the Nematoda. Philos Trans R Soc Lond B Biol Sci 2001, 356:1521-1531.

25. Schierenberg $E$ : Three sons of fortune: early embryogenesis, evolution and ecology of nematodes. Bioessays 2001, 23:841-847.

26. Lahl V, Halama C, Schierenberg E: Comparative and experimental embryogenesis of Plectidae (Nematoda). Dev Genes Evol 2003, 213:18-27.

27. Lahl V, Schulze J, Schierenberg E: Differences in embryonic pattern formation between Caenorhabditis elegans and its close parthenogenetic relative Diploscapter coronatus. Int J Dev Biol 2009, 53:507-515.

28. Bento G, Ogawa A, Sommer RJ: Co-option of the hormone-signalling module dafachronic acid-DAF-12 in nematode evolution. Nature 2010 466:494-497.

29. Kiontke K, Fitch DH: Phenotypic plasticity: different teeth for different feasts. Curr Biol 2010, 20:710-712.

30. Wiegner O, Schierenberg E: Regulative development in a nematode embryo: a hierarchy of cell fate transformations. Dev Biol 1999, 215:1-12.

31. Voronov DA, Panchin Y: Cell lineage in marine nematode Enoplus brevis. Development. 1998, 125:143-150.

32. Schierenberg E: Unusual cleavage and gastrulation in a freshwater nematode: developmental and phylogenetic implications. Dev Genes Evol 2005, 215:103-108.

33. Schulze J, Schierenberg E: Cellular pattern formation, establishment of polarity and segregation of colored cytoplasm in embryos of the nematode Romanomermis culicivorax. Dev Biol 2008, 315:426-436.

34. Schulze J, Schierenberg E: Embryogenesis of Romanomermis culicivorax: an alternative way to construct a nematode. Dev Biol 2009, 334:10-21.

35. Voronov DA: Comparative embryology of nematodes and the law of embryo similarity [in Russian]. Zh Obshch Biol 2001, 62:34-48.

36. Aleshin W: Whether variable cleavage of Enoplida (Nematoda) is primitive? Notes to D.A. Voronov article "Comparative embryology of Nematoda and the law of embryologic similarity" [in Russian]. Zh Obshch Biol 2004, 65:74-80.

37. Deppe U, Schierenberg E, Cole T, Krieg C, Schmitt D, Yoder B, von Ehrenstein $\mathrm{G}$ : Cell lineages of the embryo of the nematode Caenorhabditis elegans. Proc Natl Acad Sci USA 1978, 75:376-380.

38. Costello DP: On the orientation of centrioles in dividing cells, and its significance: a new contribution to spindle mechanics. Biol Bull 1961, 120:285-312.

39. Thery M, Bornens M: Cell shape and cell division. Curr Opin Cell Biol 2006, 18:648-657.

40. Voronov DA, Panchin YV, Spiridonov SE: Nematode phylogeny and embryology. Nature 1998, 395:28.
41. Schierenberg E: Reversal of cellular polarity and early cell-cell interaction in the embryos of Caenorhabditis elegans. Dev Biol 1987, 122:452-463.

42. Drozdovskiy EM: Contribution to the Analysis of the Embryogenesis of certain Adenophorea (Nematoda) [in Russian]. Reports of the Academy of Sciences of the USSR. 1969, 186:720-723.

43. Borgonie $G$, Jacobsen $K$, Coomans A: Embryonic lineage evolution in nematodes. Nematology 2000, 2:65-69.

44. Wyss U: Longidorus elongatus (Nematoda) Embryonalentwicklung. Institut für den Wissenschaftlichen Film, Göttingen, Germany; 1973, Film E2046.

45. Laugsch M, Schierenberg E: Differences in maternal supply and early development of closely related nematode species. Int J Dev Biol 2004 48:655-662.

46. Hyman AA: Centrosome movement in the early divisions of Caenorhabditis elegans: a cortical site determining centrosome position. J Cell Biol 1989, 109:1185-1193.

47. Gönczy P, Rose LS: Asymmetric cell division and axis formation in the embryo. WormBook The C. elegans Resarch Community'; 2005 [http://www. wormbook.org].

48. Gabriel WN, McNuff R, Patel SK, Gregory TR, Jeck WR, Jones CD, Goldstein B: The tardigrade Hypsibius dujardini, a new model for studying the evolution of development. Dev Biol 2007, 312:545-559.

49. Aguinaldo AM, Turbeville JM, Linford LS, Rivera MC, Garey JR, Raff RA, Lake JA: Evidence for a clade of nematodes, arthropods and other moulting animals. Nature 1997, 387:489-493.

50. Hejnol A, Schnabel R: The eutardigrade Thulinia stephaniae has an indeterminate development and the potential to regulate early blastomere ablations. Development 2005, 132:1349-1361.

51. Priess JR, Hirsh DI: Caenorhabditis elegans morphogenesis: the role of the cytoskeleton in elongation of the embryo. Dev Biol 1986, 117:156-173.

52. Azevedo RB, Lohaus R, Braun V, Gumbel M, Umamaheshwar M, Agapow PM, Houthoofd W, Platzer U, Borgonie G, Meinzer HP, Leroi AM: The simplicity of metazoan cell lineages. Nature 2005, 433:152-156.

53. True JR, Haag ES: Developmental system drift and flexibility in evolutionary trajectories. Evol Dev 2001, 3:109-119.

54. Wylie C: Germ cells. Cell 1999, 96:165-174.

55. Kiontke K, Gavin NP, Raynes Y, Roehrig C, Piano F, Fitch DH: Caenorhabditis phylogeny predicts convergence of hermaphroditism and extensive intron loss. Proc Natl Acad Sci USA 2004, 101:9003-9008.

56. Keating $\mathrm{HH}$, White JG: Centrosome dynamics in early embryos of Caenorhabditis elegans. J Cell Sci 1998, 111(Pt 20):3027-3033.

57. Kemphues K, Strome S: Fertilization and establishment of polarity in the embryo. In C elegans II. Edited by: Riddle DL, Blumenthal T, Meyer BJ, Priess J. New York: Cold Spring Harbor Laboratory Press; 1997:.

58. Cowan CR, Hyman AA: Asymmetric cell division in C. elegans: cortical polarity and spindle positioning. Annu Rev Cell Dev Biol 2004, 20:427-453.

59. Krueger LE, Wu JC, Tsou MF, Rose LS: LET-99 inhibits lateral posterior pulling forces during asymmetric spindle elongation in C. elegans embryos. J Cell Biol 2010, 189:481-495.

60. Zonies S, Motegi F, Hao Y, Seydoux G: Symmetry breaking and polarization of the $C$. elegans zygote by the polarity protein PAR-2. Development 2010, 137:1669-1677.

61. Grill SW, Hyman AA: Spindle positioning by cortical pulling forces. Dev Cell 2005, 8:461-465

62. Nguyen-Ngoc T, Afshar K, Gonczy P: Coupling of cortical dynein and G alpha proteins mediates spindle positioning in Caenorhabditis elegans. Nat Cell Biol 2007, 9:1294-1302.

63. Goldstein B, Frisse LM, Thomas WK: Embryonic axis specification in nematodes: evolution of the first step in development. Curr Bio/ 1998 8:157-160.

64. Cheng NN, Kirby CM, Kemphues KJ: Control of cleavage spindle orientation in Caenorhabditis elegans: the role of the genes par-2 and par-3. Genetics 1995, 139:549-559.

65. Tabuse Y, Izumi Y, Piano F, Kemphues KJ, Miwa J, Ohno S: Atypical protein kinase $C$ cooperates with PAR-3 to establish embryonic polarity in Caenorhabditis elegans. Development 1998, 125:3607-3614.

66. Hung TJ, Kemphues KJ: PAR-6 is a conserved PDZ domain-containing protein that colocalizes with PAR-3 in Caenorhabditis elegans embryos. Development 1999, 126:127-135. 
67. Kamath RS, Martinez-Campos M, Zipperlen P, Fraser AG, Ahringer J: Effectiveness of specific RNA-mediated interference through ingested double-stranded RNA in Caenorhabditis elegans. Genome Biol 2001, 2:1-10.

68. Hao Y, Boyd L, Seydoux G: Stabilization of cell polarity by the C. elegans RING protein PAR-2. Dev Cell 2006, 10:199-208.

69. Goldstein B, Macara IG: The PAR proteins: fundamental players in animal cell polarization. Dev Cell 2007, 13:609-622.

70. Arata Y, Lee JY, Goldstein B, Sawa H: Extracellular control of PAR protein localization during asymmetric cell division in the $C$. elegans embryo. Development 2010, 137:3337-3345

71. Bei Y, Hogan J, Berkowitz LA, Soto M, Rocheleau CE, Pang KM, Collins J, Mello CC: SRC-1 and Wnt signaling act together to specify endoderm and to control cleavage orientation in early C. elegans embryos. Dev Cell 2002, 3:113-125.

72. Berkowitz LA, Strome S: MES-1, a protein required for unequal divisions of the germline in early $C$. elegans embryos, resembles receptor tyrosine kinases and is localized to the boundary between the germline and gut cells. Development 2000, 127:4419-4431.

73. Conklin EG: The organization and cell lineage of the ascidian egg. In J Acad Nat Sci. Volume 13. Philadelphia; 1905:1-119.

74. Hibino T, Nishikata T, Nishida H: Centrosome-attracting body: a novel structure closely related to unequal cleavages in the ascidian embryo. Dev Growth Differ 1998, 40:85-95.

75. Nishikata T, Hibino T, Nishida H: The centrosome-attracting body, microtubule system, and posterior egg cytoplasm are involved in positioning of cleavage planes in the ascidian embryo. Dev Biol 1999, 209:72-85.

76. Patalano S, Pruliere G, Prodon F, Paix A, Dru P, Sardet C, Chenevert J: The aPKC-PAR-6-PAR-3 cell polarity complex localizes to the centrosome attracting body, a macroscopic cortical structure responsible for asymmetric divisions in the early ascidian embryo. J Cell Sci 2006 119:1592-1603.

77. Meinhardt H: Different strategies for midline formation in bilaterians. Nat Rev Neurosci 2004, 5:502-510.

78. Schnabel R, Priess JR: Specification of Cell Fates in the Early Embryo. In C elegans II. Edited by: Riddle DL, Blumenthal T, Meyer BJ, Priess J. New York: Cold Spring Harbor Laboratory Press; 1997:.

79. Goldstein B: An analysis of the response to gut induction in the $C$. elegans embryo. Development 1995, 121:1227-1236.

80. Eisenmann DM: Wnt signaling. Wormbook The C. elegans Resarch Community'; 2005 [http://www.wormbook.org].

81. Priess JR: Notch signaling in the C. elegans embryo. WormBook The C. elegans Resarch Community'; 2005 [http://www.wormbook.org].

82. Goldstein B: Establishment of gut fate in the $E$ lineage of $C$. elegans: the roles of lineage-dependent mechanisms and cell interactions. Development 1993, 118:1267-1277.

\section{Submit your next manuscript to BioMed Central and take full advantage of:}

- Convenient online submission

- Thorough peer review

- No space constraints or color figure charges

- Immediate publication on acceptance

- Inclusion in PubMed, CAS, Scopus and Google Scholar

- Research which is freely available for redistribution

Submit your manuscript at www.biomedcentral.com/submit
Biomed Central 